\title{
Collagen Peptide in a Combinatorial Treatment with Lactobacillus rhamnosus Inhibits the Cariogenic Properties of Streptococcus mutans: An In Vitro Study
}

\author{
Hee-Young Jung ${ }^{1}$, Jian-Na Cai ${ }^{1}$, Sung Chul Yoo ${ }^{2}$, Seon-Hwa Kim ${ }^{2}$, Jae-Gyu Jeon ${ }^{1,3}$ and Dongyeop Kim ${ }^{1,3, *(D)}$ \\ 1 Department of Preventive Dentistry, School of Dentistry, Jeonbuk National University, Jeonju 54896, Korea; \\ ghgh7090@jbnu.ac.kr (H.-Y.J.); caijianna1110@163.com (J.-N.C.); dentjjk@jbnu.ac.kr (J.-G.J.) \\ 2 Vixxol Corporation, Gunpo 15807, Korea; scyoo@vixxol.com (S.C.Y.); seonhkim@vixxol.com (S.-H.K.) \\ 3 Institute of Medical Information Convergence Research, Jeonbuk National University, Jeonju 54896, Korea \\ * Correspondence: biofilmkim@jbnu.ac.kr
}

check for updates

Citation: Jung, H.-Y.; Cai, J.-N.; Yoo, S.C.; Kim, S.-H.; Jeon, J.-G.; Kim, D. Collagen Peptide in a Combinatorial Treatment with Lactobacillus rhamnosus Inhibits the Cariogenic Properties of Streptococcus mutans: An In Vitro Study. Int. J. Mol. Sci. 2022, 23, 1860. https://doi.org/ 10.3390/ijms23031860

Academic Editor: Jintae Lee

Received: 13 January 2022

Accepted: 4 February 2022

Published: 7 February 2022

Publisher's Note: MDPI stays neutral with regard to jurisdictional claims in published maps and institutional affiliations.

Copyright: (c) 2022 by the authors. Licensee MDPI, Basel, Switzerland. This article is an open access article distributed under the terms and conditions of the Creative Commons Attribution (CC BY) license (https:/ / creativecommons.org/licenses/by/ $4.0 /)$.

\begin{abstract}
Dental caries is caused by the formation of cariogenic biofilm, leading to localized areas of enamel demineralization. Streptococcus mutans, a cariogenic pathogen, has long been considered as a microbial etiology of dental caries. We hypothesized that an antagonistic approach using a prebiotic collagen peptide in combination with probiotic Lactobacillus rhamnosus would modulate the virulence of this cariogenic biofilm. In vitro $S$. mutans biofilms were formed on saliva-coated hydroxyapatite discs, and the inhibitory effect of a combination of L. rhamnosus and collagen peptide on S. mutans biofilms were evaluated using microbiological, biochemical, confocal imaging, and transcriptomic analyses. The combination of L. rhamnosus with collagen peptide altered acid production by S. mutans, significantly increasing culture $\mathrm{pH}$ at an early stage of biofilm formation. Moreover, the 3D architecture of the $S$. mutans biofilm was greatly compromised when it was in the presence of L. rhamnosus with collagen peptide, resulting in a significant reduction in exopolysaccharide with unstructured and mixed bacterial organization. The presence of L. rhamnosus with collagen peptide modulated the virulence potential of $S$. mutans via down-regulation of $e n o, l d h$, and $a t p D$ corresponding to acid production and proton transportation, whereas $a g u D$ associated with alkali production was up-regulated. Gly-Pro-Hyp, a common tripeptide unit of collagen, consistently modulated the cariogenic potential of $S$. mutans by inhibiting acid production, similar to the bioactivity of a collagen peptide. It also enhanced the relative abundance of commensal streptococci (S. oralis) in a mixedspecies biofilm by inhibiting $S$. mutans colonization and dome-like microcolony formation. This work demonstrates that food-derived synbiotics may offer a useful means of disrupting cariogenic communities and maintaining microbial homeostasis.
\end{abstract}

Keywords: synbiotics; probiotics; prebiotics; cariogenic biofilms; metabolic interference; acidogenicity; aciduricity

\section{Introduction}

Dental caries is one of the most prevalent biofilm and diet-dependent oral diseases worldwide, resulting in annual expenditures of over USD 40 billion and afflicting mostly underprivileged persons [1,2]. In this disease, a cariogenic pathogen, Streptococcus mutans, is often found along with other microorganisms [3-5]. A sugar-rich diet (i.e., a diet rich in processed foods) promotes $S$. mutans assembly with an exopolysaccharide (EPS)-rich matrix via glucosyltransferase (Gtf) exoenzymes and acidifies the microenvironment through constant sugar catabolism [6]. An EPS-rich and acidic microenvironment is a key virulence factor that acts as a three-dimensional (3D) scaffold and protection barrier to diffusion, enhancing the cariogenic potential of an S. mutans-dominated biofilm. In particular, a bacteria-derived EPS-matrix enhances drug resistance, as adhered microbes are enmeshed within a shield that protects against antibiotics $[7,8]$. 
Oral probiotics have been considered an alternative approach to the disruption of cariogenic biofilms $[9,10]$. The administration of oral probiotics to cariogenic microbiota helps maintain a healthy microbial community by suppressing bacterial colonization and the virulence mechanism of $S$. mutans. However, current studies focused on the preventative potential of conventional probiotics (which have mostly examined Lactobacillus used in treating gastrointestinal disorders) on dental caries have shown inconsistent results [11,12]. Even when the Lactobacillus rhamnosus strain GG is shown to have the potential for modulating the virulence of $S$. mutans-mediated biofilms [12,13], it may have a limited ability to prevent colonization of $S$. mutans on the tooth surface [14]. Since lactobacilli are often considered late colonizers of the pellicle, probiotics alone are insufficient to prevent cavities $[10,11]$. To accelerate the use of conventional probiotics, which have well-characterized and well-documented health benefits, an adjuvant for that promotes the colonization of probiotics while modulating the virulence factor of the pathogen is necessary $[15,16]$.

Prebiotics impact the functional potential of bacterial cells $[15,16]$. Therefore, probiotics are in a combination of prebiotics (referred to as synbiotics), that synergically modulate the virulence of $S$. mutans and, in turn, inhibit cariogenic biofilm formation [17]. An enhanced understanding of the preventive implications of synbiotics may allow for improved antibiofilm strategies that overcome the limitations of current modalities by applying antibiotics. We hypothesized that probiotic L. rhamnosus administered in combination with prebiotic collagen peptide $(C P)$ would thwart $S$. mutans outgrowth under cariogenic conditions. To address this, we examined whether L. rhamnosus modulated the virulence factors of $S$. mutans in the presence of $C P$ by modifying a cariogenic biofilm structure, while rearranging bacterial organization to cause defective EPS matrix formation. We further investigated whether the introduction of synbiotics promotes the homeostasis of commensal via modifying acidogenic and aciduric properties of $S$. mutans.

Thus, this study aims to investigate the inhibitory effect of CP in a combination with L. rhamnosus on cariogenic potential of $S$. mutans using a well-established saliva-coated hydroxyapatite in vitro biofilm model.

\section{Results}

\subsection{Effects of Prebiotic Collagen Peptide and Probiotic L. rhamnosus on Bacterial Cell Growth}

The influences of CP on the cell viability of S. mutans and L. rhamnosus were determined by agar plate assay. To investigate the effect of CP supplementation on bacterial growth, serially diluted bacterial culture (ranged $10^{3-7} \mathrm{CFU} / \mathrm{mL}$ ) was spotted on a CP-supplemented agar plate $(0-5 \mathrm{mg} / \mathrm{mL})$. As shown in Figure $1 \mathrm{~A}$, there was no growth-inhibitory activity against either $S$. mutans or L. rhamnosus. This is consistent with the idea of prebiotics, according to which the agent does not kill or inhibit the cell growth $[15,18]$. We further conducted a competition assay to evaluate whether L. rhamnosus (ranged $10^{5-7} \mathrm{CFU} / \mathrm{mL}$ ) inhibits pathogenic $S$. mutans $\left(10^{5} \mathrm{CFU} / \mathrm{mL}\right)$ growth on a CP-supplemented agar plate (Figure 1B). There was no direct inhibition of $S$. mutans by L. rhamnosus regardless of the presence or absence of CP.

\subsection{Effect of Collagen Peptide on Glycolytic Acid Production by S. mutans and L. rhamnosus}

A glycolytic $\mathrm{pH}$ drop assay was performed to evaluate the acid production ability of planktonic $S$. mutans in coexistence with L. rhamnosus in the presence of CP. As shown in Figure 2, over the 90 min experiment period, CP increased the $\mathrm{pH}$ of $S$. mutans cell suspension (low aciduricity) regardless of the presence of L. rhamnosus. Following CP treatment, the rate of acid production of $S$. mutans was reduced by $82 \%(p<0.001)$. In parallel with a reduction in $\left[\mathrm{H}^{+}\right]$concentration of $S$. mutans, $\mathrm{CP}$ also inhibited glycolytic $\mathrm{pH}$ drop of L. rhamnosus itself or together with $S$. mutans, resulting in a $94 \%$ and $75 \%$ reduction (versus vehicle control (without $\mathrm{CP}$ )), respectively (low acidogenicity). 
(A)

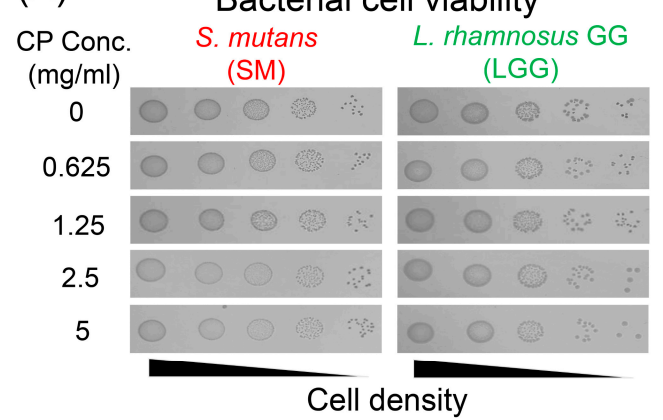

(B)

Cell-cell interaction

With/without CP
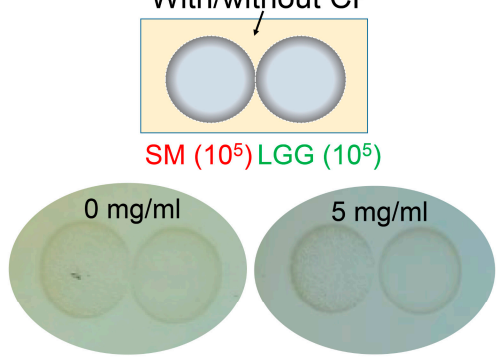

Figure 1. Effects of collagen peptide (CP) on bacterial cell viability and cell-cell interaction between S. mutans and L. rhamnosus. (A) Effects of $\mathrm{CP}$ on the cell viability of S. mutans and L. rhamnosus. $\mathrm{CP}$ demonstrated no inhibitory activity on the growth of $S$. mutans and L. rhamnosus in brain heart infusion (BHI) agar plate. (B) Cell-cell interaction between S. mutans and L. rhamnosus with or without CP. Where one strain is capable of competing with another, the growth of spotted bacterial macrocolony shows defective patterns by another (left, S. mutans (SM); right, L. rhamnosus (LGG)). There is no direct growth competition between two bacteria in the BHI agar plate.

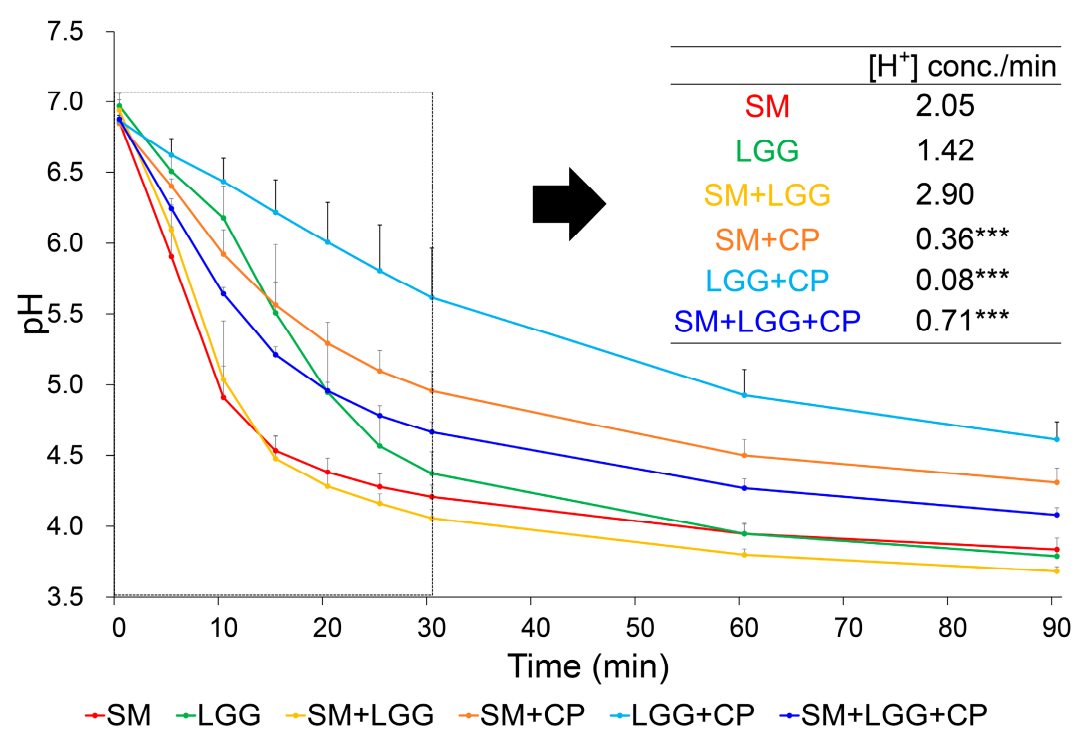

Figure 2. Effects of $\mathrm{CP}$ on the glycolytic $\mathrm{pH}$ drop by S. mutans and L. rhamnosus planktonic cells. The initial rate of the $\mathrm{pH}$ drop was calculated by hydrogen ion $\left(\mathrm{H}^{+}\right)$released for $30 \mathrm{~min}$ (dashed blot box). The molar concentration of $\mathrm{H}^{+}$in the solution was estimated via the equation: $\left[\mathrm{H}^{+}\right]=10^{-\mathrm{pH}}$. Data represent mean \pm standard deviations (SD) $(n=3)$. Values are significantly different from each other ( $t$-test for a pairwise comparison, with CP vs. without CP) at ${ }^{* * *} p<0.001$.

\subsection{Effect of Collagen Peptide in a Combination of L. rhamnosus on the Biofilm Formation} of S. mutans

In single- and dual-species biofilms (42 h-old), colonized viable cells of $S$. mutans and L. rhamnosus were between $10^{8}$ to $10^{9} \mathrm{CFU} / \mathrm{mL}$, indicating that both were well colonized on the hydroxyapatite (HA) discs. However, the total biomass (dry weight) of L. rhamnosus was 10 times less than that of the S. mutans biofilm and, moreover, that of the coculture of S. mutans and L. rhamnosus was significantly reduced without drastic changes to the S. mutans cells in the biofilms (Figure 3A). We further tested whether the different inoculums of L. rhamnosus $\left(10^{5}\right.$ to $\left.10^{7} \mathrm{CFU} / \mathrm{mL}\right)$ affected the biomass and culture $\mathrm{pH}$ in the presence of CP (5 mg/mL). The results showed that $10^{7} \mathrm{CFU} / \mathrm{mL}$ L. rhamnosus with CP slightly reduce the dry weight while a culture $\mathrm{pH}$ of biofilm was increased to the critical $\mathrm{pH}$ point (about $\mathrm{pH}$ 5.0) (Figure 3B). In sum, the combination of probiotic L. rhamnosus 
and prebiotic CP exhibited no bactericidal effect on $S$. mutans but did interfere with its metabolic traits (e.g., reduced acid production).

(A)

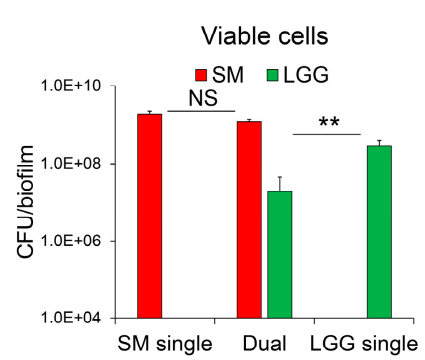

Biofilm formation (single- vs. dual-species)

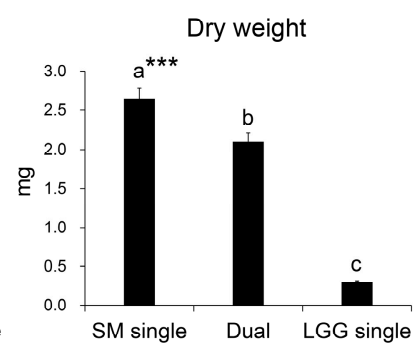

(B)

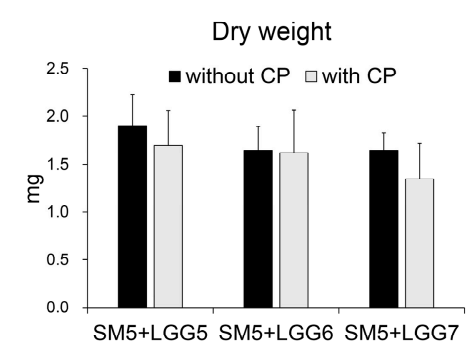

Biofilm formation (LGG with/without CP)

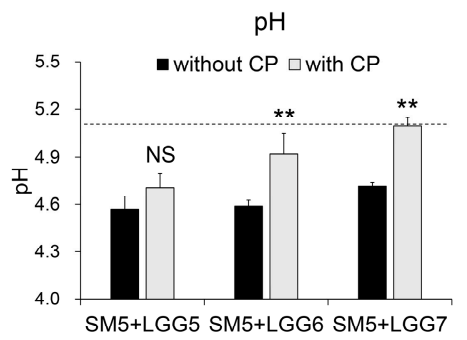

Figure 3. Biofilm formation of S. mutans and L. rhamnosus single or dual-species bioflim (42 h-old) with or without CP. (A) Viable cell counts (colony forming units (CFU)/biofilm) and dry weight of $S$. mutans and L. rhamnosus single or dual-species bioflim. The inoculum populations of both $S$. mutans and L. rhamnosus were $10^{5}$ colony-forming units (CFU)/mL. (B) Dry weight and culture $\mathrm{pH}$ of dual-species biofilm with or without CP. Dot-line indicates the $\mathrm{pH}$ value of $\mathrm{S}$. mutans $\left(10^{5}\right)$ and L. rhamnosus $\left(10^{7}\right)$ is above the critical $\mathrm{pH}$ of demineralization ( $\mathrm{pH}$ 5.0). Data represent mean $\pm \mathrm{SD}$ $(\mathrm{n}=4)$. The data were subjected to analysis of variance (ANOVA) in the Tukey's HSD test for a multiple comparison or student's $t$-test for a pairwise comparison (single vs. dual or without CP vs. with $\mathrm{CP}$ ). Values followed by different letters (a-c in a multiple comparison) are significantly different from each other at ${ }^{* *} p<0.01,{ }^{* * *} p<0.001$. NS, no significance.

Next, the combined effect of L. rhamnosus and CP on S. mutans biofilm development was assessed. Using an established biofilm model (Figure 4A), in which the viable cell, dry weight, culture $\mathrm{pH}$, and 3D architecture of mono- or dual-species biofilms between $S$. mutans and L. rhamnosus in the presence or absence of $\mathrm{CP}$ were determined at three different times $(19,23$, and $43 \mathrm{~h})$. These different time points were corresponded to initial attachment, early-stage, and mature biofilms, reflecting intermixed cell attachment to microcolony formation (Figure 4B). As shown in Figure 4D,E, the presence of L. rhamnosus with/without $\mathrm{CP}$ resulted in reduction in dry weight, while the culture $\mathrm{pH}$ of the biofilm was significantly increased. The viable cell counts were significantly decreased in the presence of L. rhamnosus and CP, especially at the stage for the initial colonization (19 h), which showed a 2-log CFU reduction (Figure 4C). In contrast, CP alone did not display any influence on S. mutans biofilm formation across the entire experiment period.

Since total biomass reflects the sum of cells and the extracellular matrix, we also investigated the 3D architecture of the biofilm by using bacterial species-specific probes and the EPS labeling technique. This was essential to determining the bacterial cell assembly and EPS distribution in the presence of L. rhamnosus and CP. To further determine any inhibitory effects of the combinatorial treatment of L. rhamnosus with $\mathrm{CP}$ on the alternation of the $3 \mathrm{D}$ architecture of the S. mutans biofilm, we performed confocal imaging with quantitative computational analysis.

Representative images showed that L. rhamnosus combined with CP resulted in a marked impairment of EPS-matrix accumulation and microcolony development, which exhibited sparse amounts of EPS randomly interspersed among bacterial cells without any structural organization, resulting in reduced bacteria-EPS co-localization (Figure 5A). This result was consistent with computational imaging analysis, which showed approximately 9 times less EPS in biofilms treated with L. rhamnosus and CP (vs. single S. mutans biofilms) (Figure 5B). Furthermore, a close-up image of the selected area revealed that the presence of $\mathrm{CP}$ or L. rhamnosus partially resulted in small microcolony and loose structure of $S$. mutans clusters, but that a combination of L. rhamnosus and $\mathrm{CP}$ further inhibited the accumulation of S. mutans, resulted in cell clusters intermixed with L. rhamnosus (Figure 5C). In sum, the data indicate that a combination of $\mathrm{CP}$ and L. rhamnosus substantially inhibits initial 
colonization of S. mutans and EPS-matrix formation, thereby reducing the bulk and density of infection.

(A)

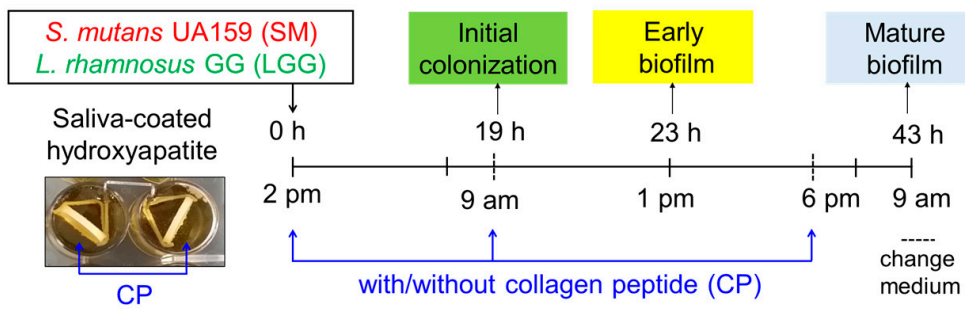

(B)
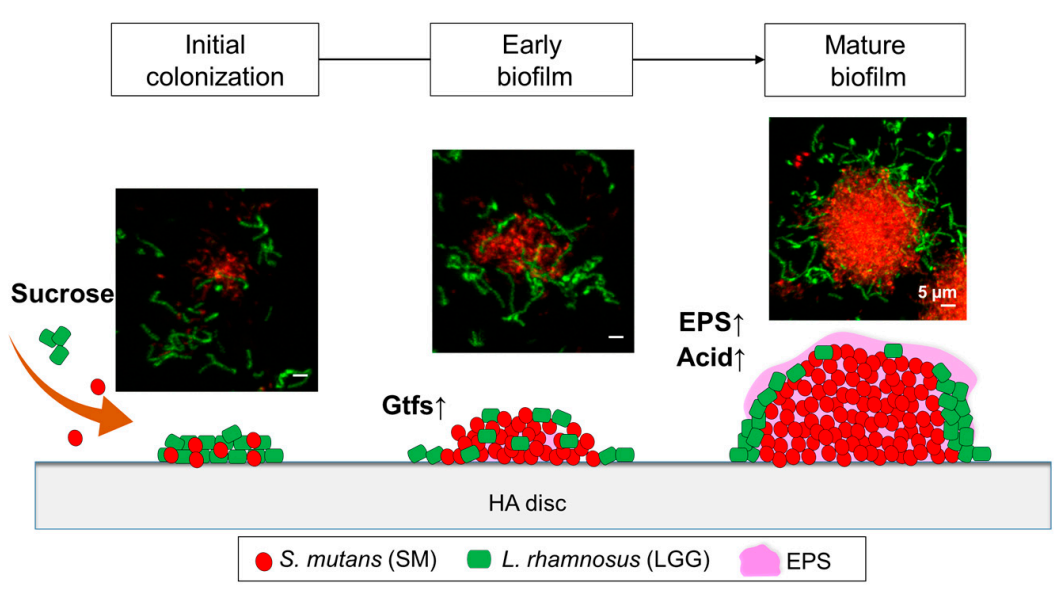

(C)

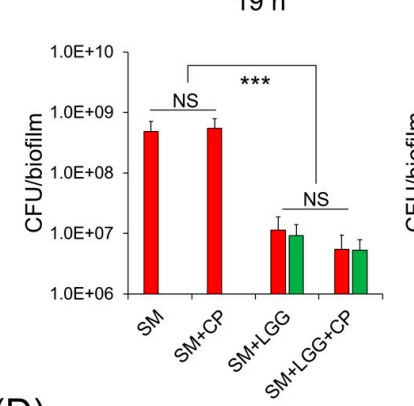

(D)
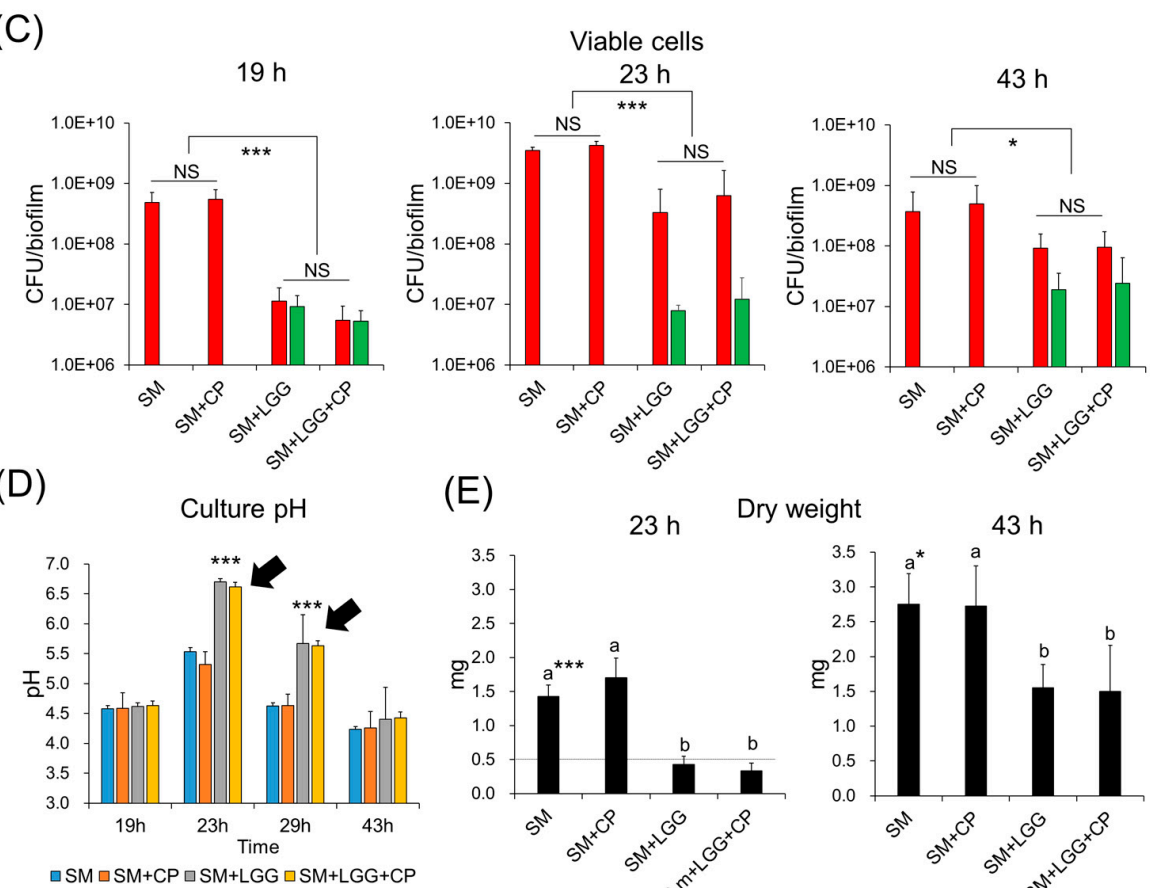

(E)
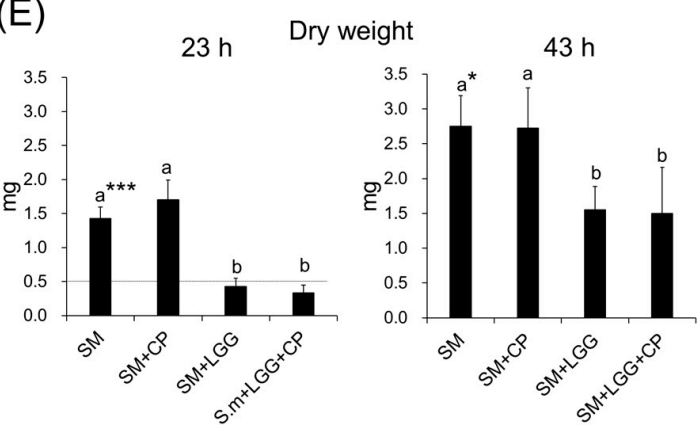

Figure 4. Experiment scheme and microbiological and biochemical analysis of biofilms. (A) Experiment design for biofilm formation and $\mathrm{CP}$ treatment. The mixed population was inoculated in $2.8 \mathrm{~mL}$ of medium containing $1 \%(w / v)$ sucrose with/without $\mathrm{CP}$ and incubated at $37{ }^{\circ} \mathrm{C}$ and $5 \%$ $\mathrm{CO}_{2}$. The culture medium containing $1 \%(w / v)$ sucrose was changed twice daily (at $9 \mathrm{am}(19 \mathrm{~h})$ and $6 \mathrm{pm}(28 \mathrm{~h}))$. (B) Schematic diagram of development stages of biofilm. Viable cell counts (C), culture $\mathrm{pH}$ (D) and dry weight (E) of S. mutans single biofilm or cocultured bioflim with L. rhamnosus in the presence or absence of CP. Dot-line indicates the detection limits of dry weight measurement. Data represent mean $\pm \operatorname{SD}(n=4)$. Values followed by different letters $(\mathrm{a}, \mathrm{b})$ are significantly different from each other at ${ }^{*} p<0.05,{ }^{* * *} p<0.001$. NS, no significance. 
(A)

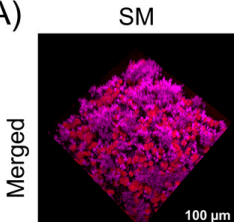

$\mathrm{SM}+\mathrm{CP}$

$S M+L G G$

$S M+L G G+C P$

(B)
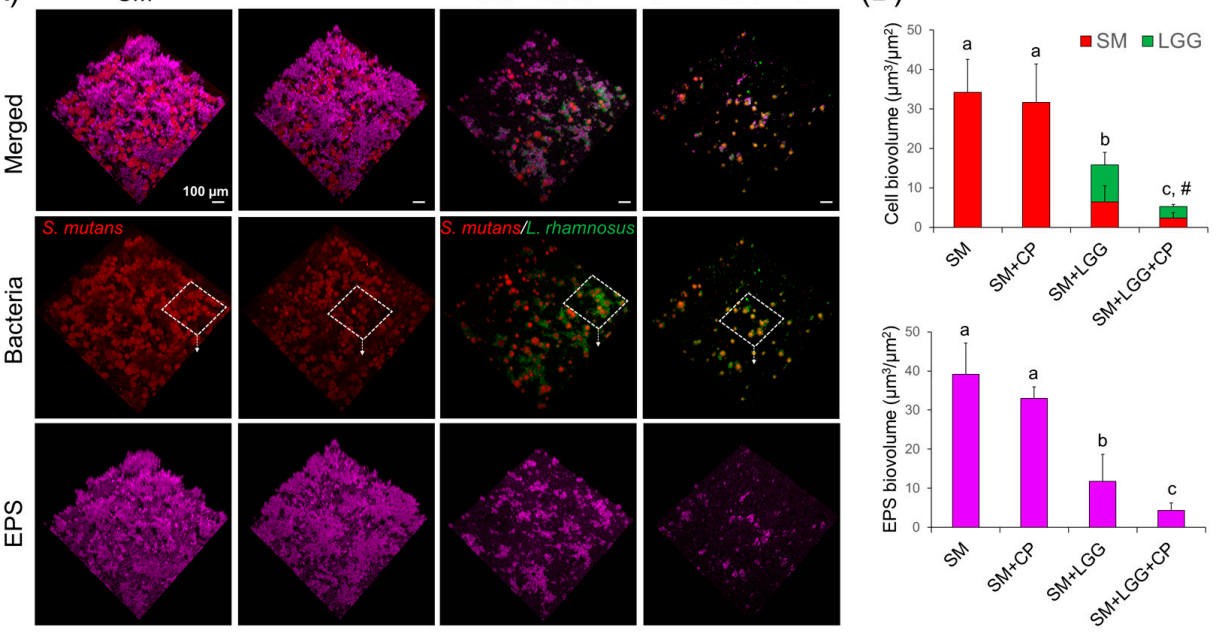

(C)
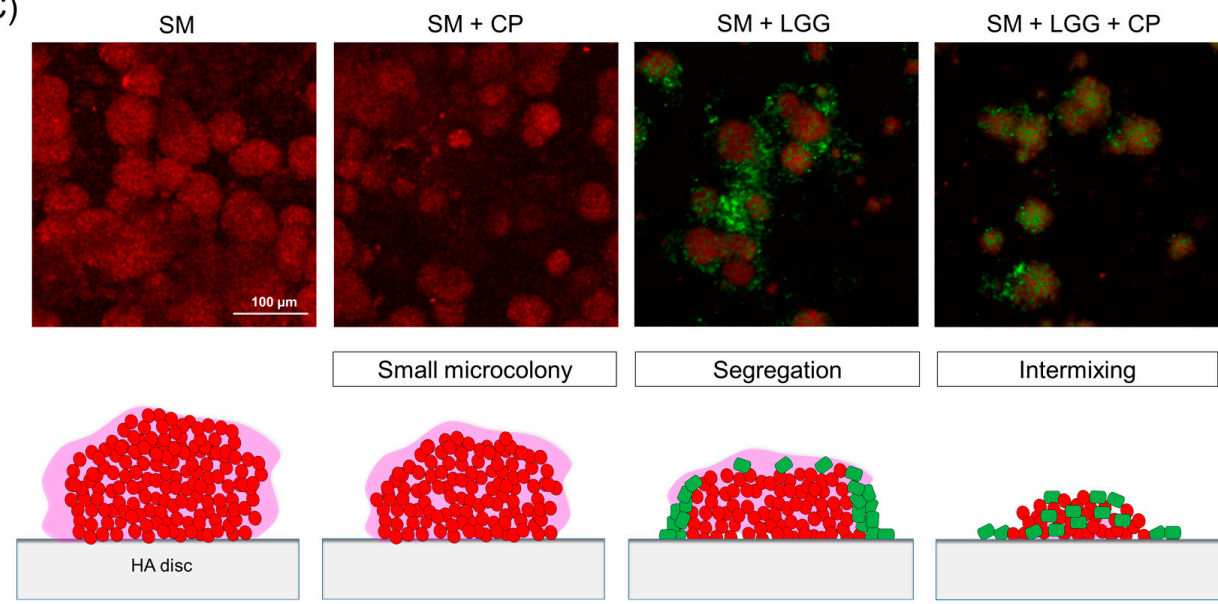

Segregation

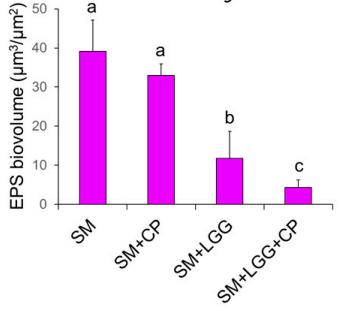

igure 5. Three-dimensional (3D) architecture and quantitative computational analysis of $S$. mutans biofilm (23 h-old) with or without L. rhamnosus and CP. (A) Representative confocal images, S. mutans and L. rhamnosus cells are depicted in red and green, respectively; while the EPS-matrix is depicted in purple. (B) Quantitative analysis of bacteria cell and EPS biovolume was performed using COMSTAT. (C) Close-up images of selected areas (dashed box) and schematic diagram of biofilm model. Data represent mean $\pm \mathrm{SD}(n=10)$. Values followed by different letters $(\mathrm{a}-\mathrm{c})$ are significantly different from each other $(p<0.001)$. \# indicates that cell biovolume of both $S$. mutans and L. rhamnosus in the presence of $\mathrm{CP}(\mathrm{SM}+\mathrm{LGG}+\mathrm{CP})$ is significantly different in a pair comparison with vehicle control (SM + LGG). SM, S. mutans; LGG, L. rhamnosus GG; CP, collagen peptide.

\subsection{Effect of Collagen Peptide in a Combination of L. rhamnosus on the Transcriptomic Changes of} S. mutans Biofilm

To further understand mechanism of action of a combinatorial treatment of L. rhamnosus with $\mathrm{CP}$, we examined the potential effects of the combinatorial treatment on the expression of specific $S$. mutans genes using quantitative real-time PCR (qRT-PCR). The genes selected for qRT-PCR were related to a transcription factor of acid production (eno and $l d h$ ) and acid tolerance ( $a t p D$ and $a g u D$ ). The gene expression of $S$. mutans in an early-stage biofilm were analyzed since the combinatorial treatment drastically modified culture $\mathrm{pH}$ and altered 3D architecture of biofilms at $23 \mathrm{~h}$. As shown in Figure 6, L. rhamnosus, together with CP, repressed the expression of genes associated with glycolysis by $S$. mutans. In addition, the expression of $l d h$, which encodes $S$. mutans lactate dehydrogenase (responsible to acidogenicity) was down-regulated, while $a g u D$ expression, which is related to acid tolerance, was up-regulated (promoting alkali (e.g., ammonia) production) in the presence of L. rhamnosus and CP. This was consistent with results from the glycolytic $\mathrm{pH}$ drop assay, 
in which CP decreased the acid production rate (Figure 2). Since eno and $l d h$ are involved in the synthesis of pyruvate and lactate, it is possible that the combinatorial treatment is capable of inhibiting acid production. Additionally, the atpD gene corresponding to proton transportation through F-ATPase was also repressed. However, $a g u D$ is associated with agmatine catabolism via the agmatine deiminase system (AgDS), a pathway that utilizes an agmatine deiminase to hydrolyze agmatine into putrescine, during which concomitantly released ammonia alters the acidic environment [19]. Thus, upregulation of $a g u D$ expression by combinatorial treatment is also consistent with an increase in culture $\mathrm{pH}$ (up to pH 6.6) (Figure 4D). In sum, the data suggest that L. rhamnosus with CP can modulate the cariogenic potential of $S$. mutans by regulating acidogenicity- and acid tolerance-related gene expression.

(A)

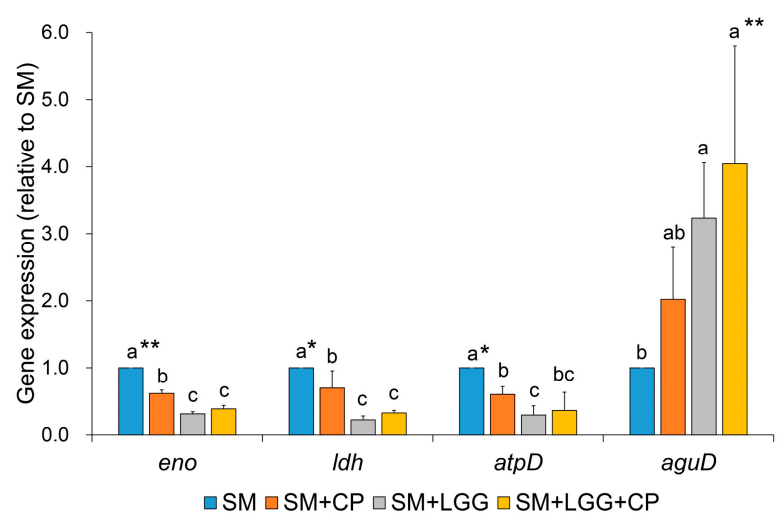

(B)

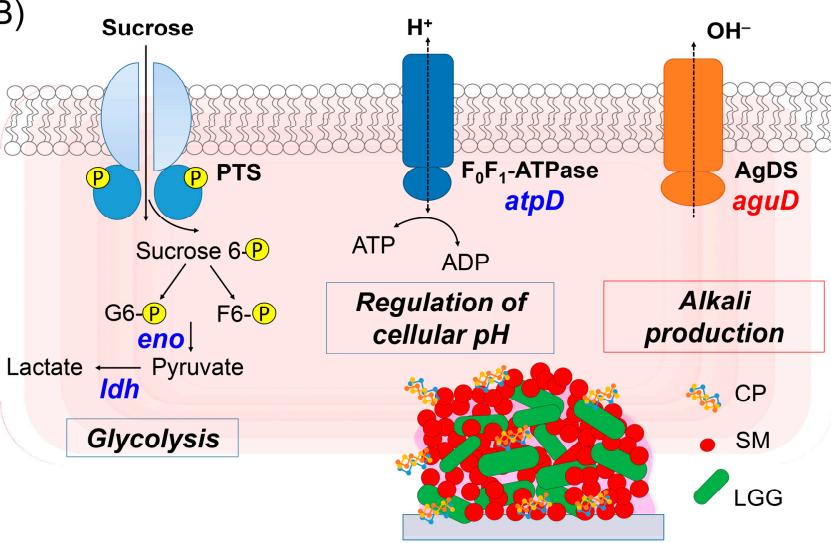

Figure 6. Gene expression of S. mutans biofilm with or without L. rhamnosus and CP (A) and postulated pathways of acid production and acid tolerance in S. mutans (B). The data reveal that the genes related to acidogenic and aciduric properties of $S$. mutans was inhibited in the presence of L. rhamnosus and $C P$ via down-regulation of $e n o, l d h$, and $a t p D$ genes (associated with acid production; blue letters), whereas upregulation of $a g u D$ gene (associated with alkali production; red letters). Data represent mean $\pm \mathrm{SD}(n=4)$. Values followed by different letters $(\mathrm{a}-\mathrm{c})$ are significantly different from each other at ${ }^{*} p<0.05,{ }^{* *} p<0.01$. SM, S. mutans; LGG, L. rhamnosus GG; CP, collagen peptide.

2.5. Effects of Glycine-Proline-Hydroxyproline (Gly-Pro-Hyp) and the Presence of L. rhamnosus on the Acid Production Ability of S. mutans

Since collagen is composed of various peptides and amino acids, we further assessed the potential effect of a collagen tripeptide rich in Gly-Pro-Hyp, and glycine (Gly), one of most abundant amino acids in $\mathrm{CP}$, on glycolytic acid production by $S$. mutans and L. rhamnosus. As shown in Table 1, treatment with Gly-Pro-Hyp or Gly significantly decreased the extracelluar $\left[\mathrm{H}^{+}\right]$concentration of the bacterial culture, which showed a similar inhibition activity to CP. Furthermore, Gly-Pro-Hyp exhibited the lowest $\left[\mathrm{H}^{+}\right]$ production rate $(0.04)$ compared to vehicle control (expressed as 1.00). 
Table 1. Profiles of glycolytic pH drop by CP, Gly-Pro-Hyp, and Gly treatments.

\begin{tabular}{|c|c|c|c|c|c|}
\hline Group & $\mathrm{pH}$ at $30 \mathrm{~min}$ & Delta $\mathrm{pH}^{1}$ & {$\left[\mathrm{H}^{+}\right]$Conc. $(\mu \mathrm{M})^{2}$} & Rate ([H+]/min) & Relative Ratio $^{3}$ \\
\hline Control & $4.73 \pm 0.13^{c, 4}$ & $2.26 \pm 0.08^{a}$ & $19.27 \pm 5.52^{a}$ & $0.64 \pm 0.18^{a}$ & $1.00 \pm 0.00^{\mathrm{a}}$ \\
\hline $\mathrm{CP}$ & $5.53 \pm 0.28^{a b}$ & $1.18 \pm 0.15^{c}$ & $3.24 \pm 2.05^{b c}$ & $0.11 \pm 0.07^{b c}$ & $0.15 \pm 0.06^{b c}$ \\
\hline Gly-Pro-Hyp & $5.97 \pm 0.37^{\mathrm{a}}$ & $0.75 \pm 0.22^{d}$ & $1.20 \pm 1.06^{\mathrm{c}}$ & $0.04 \pm 0.04^{c}$ & $0.05 \pm 0.04^{\mathrm{c}}$ \\
\hline Gly & $5.31 \pm 0.20^{b}$ & $1.44 \pm 0.10^{b}$ & $5.10 \pm 2.35^{b}$ & $0.17 \pm 0.08^{b}$ & $0.25 \pm 0.05^{b}$ \\
\hline
\end{tabular}

${ }^{1}$ Delta $\mathrm{pH}$ : initial $\mathrm{pH}-\mathrm{pH}$ at $30 \mathrm{~min}$ after glucose challenge. ${ }^{2}$ The molar concentration of hydrogen ion in the solution was estimated via the equation: $[\mathrm{H}+]=10^{\text {-in situ } \mathrm{pH}} \cdot{ }^{3}$ Relative ratio to control (S. mutans + L. rhamnosus with vehicle). ${ }^{4}$ Mean $\pm \mathrm{SD}(n=3)$. Values followed by different superscripts (a-d) are significantly different from each other at $p<0.001$

\subsection{Gly-Pro-Hyp Treatment Prevented S. mutans Outgrowth and Promoted S. oralis Dominance}

To further confirm the effects of Gly-Pro-Hyp and CP on bacterial diversity in the multi-species community, we selected $S$. oralis, one of the most commonly detected pioneer colonizers in dental biofilms, together with $S$. mutans and L. rhamnosus, to form a mixedspecies biofilm (42 h-old) via ecological plaque hypothesis. According to our observations, when a biofilm was treated with either Gly-Pro-Hyp or CP, the distribution of S. mutans colonies (red) was significantly reduced, while the biovolume of $S$. oralis (blue) had increased gradually. This was especially true in presence of Gly-Pro-Hyp, which showed a 4 -fold biovolume ratio increase, but a decrease in the biovolume ratio of $S$. mutans from $63.8 \%$ to $34.4 \%$ (Figure 7 ).

(A)

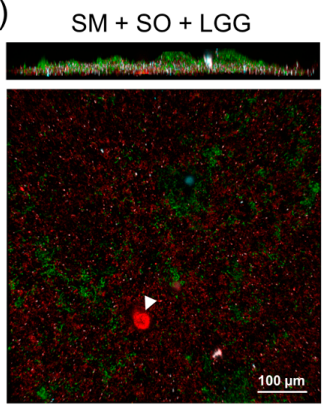

$\mathrm{SM}+\mathrm{SO}+\mathrm{LGG}+\mathrm{CP}$

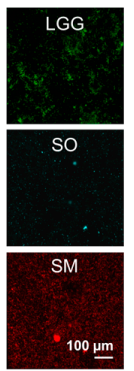

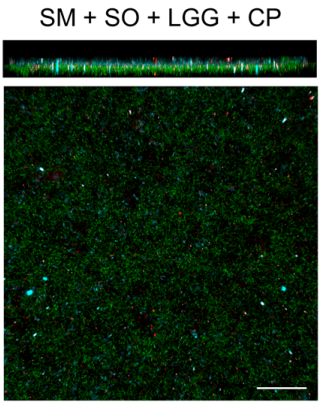

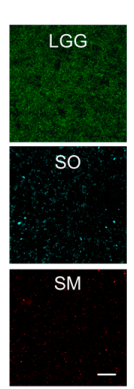

$\mathrm{SM}+\mathrm{SO}+\mathrm{LGG}+\mathrm{GPH}$
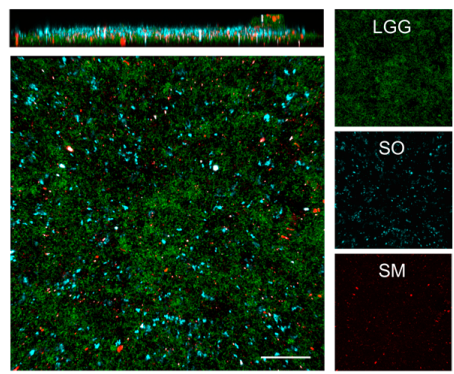

(B)

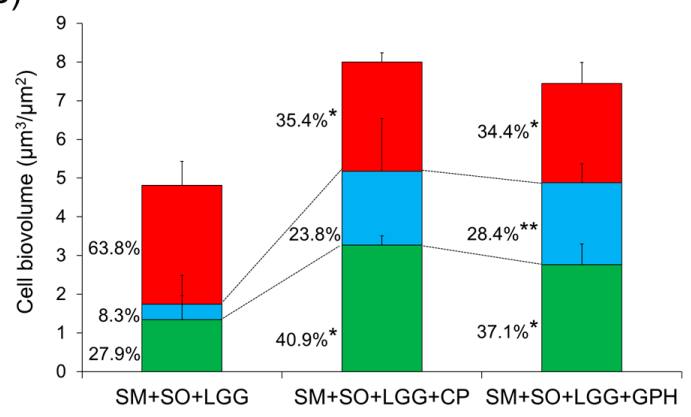

Figure 7. Effects of Gly-Pro-Hyp and $\mathrm{CP}$ on a diverse bacteria community in a multi-species biofilm (43 h-old). The mixed bacterial population was inoculated in medium containing $0.1 \%(w / v)$ sucrose and then incubated for $19 \mathrm{~h}$. Then, the initial biofilm was transferred to fresh medium containing $1 \%$ sucrose to stimulate a cariogenic challenge from $19 \mathrm{~h}$ until $43 \mathrm{~h}$ (plus change medium at $28 \mathrm{~h}$ ). (A) Representative confocal images of a multi-species biofilm. Bacterial cells were labeled with species-specific FISH probes. S. mutans, S. oralis, and L. rhamnosus cells are depicted in red, blue, and green, respectively. An arrowhead indicates S. mutans microcolony. (B) Quantitative analysis of bacteria cell (expressed as biovolume) was performed. Mean $\pm \mathrm{SD}(n=4)$. A pairwise comparison (vs. SM + SO + LGG) was conducted using student's t-test. ${ }^{*} p<0.05,{ }^{*} p<0.01 . \mathrm{SM}, \mathrm{S}$. mutans; SO, S. oralis; LGG, L. rhamnosus GG; CP, collagen peptide; GPH, Gly-Pro-Hyp. 
This result may be explained by the glycolytic $\mathrm{pH}$ drop assay, as Gly-Pro-Hyp and $\mathrm{CP}$ decreased the acidogenic and aciduric properties of the $S$. mutans (Table 1), thereby providing a more favorable condition for $S$. oralis, and, in turn, promoting the transition of virulent biofilm (mediated by outgrowth of $S$. mutans) into a less-cariogenic biofilm (S. oralis dominated).

\section{Discussion}

Previous microbiome- and imaging-based studies have revealed that a polymicrobial community acts in concert to develop dental plaque biofilms, specifically the supragingival plaque biofilms that are formed on tooth surfaces [20-22]. Dysbiosis is mediated by adhesion of cariogenic pathogens to a tooth surface under sucrose-rich and highly acidic milieu. Meanwhile, the cariogenic microbial community is shaped by physical and metabolic interactions with other microorganisms and host factors [6,23].

Depending on disease status and the maturity of the biofilms, the spatial organization of cariogenic pathogens (e.g., EPS-mediated dome-like structure) can be linked to the microbial diagnosis in dental caries along with physicochemical factors associated with localized EPS/acid production and the creation of acidic microenvironments [6,24,25]. Most approaches to the disruption of cariogenic biofilm rely on antimicrobials, though these often are thwarted by the presence of EPS acting as a protective shield, resulting in an enhanced tolerance of EPS-embedded bacteria to antimicrobials. The challenges and limitations of current modalities have generated interest in alternative therapeutic approaches. A proper therapeutic approach against cariogenic biofilms should inhibit the pathogens within the biofilm as it simultaneously disrupts matrix formation [26].

In this study, we introduce a conceptual model in which applying an antagonistic interaction between pathogen and synbiotics may be a feasible means of preventing caries. Using an experimental biofilm model, we confirmed that the presence of L. rhamnosus effectively inhibited dome-like biofilm formation by $S$. mutans (reduced dominance of $S$. mutans and EPS scaffolds within the biofilm). Concomitantly, treatment of collagen peptide (CP), together with L. rhamnosus, reduced the total biovolume of the biofilm. We also observed that $\mathrm{CP}$ is a key modulator of acid production, rendering it capable of altering the microenvironment and maintaining neutral $\mathrm{pH}$ in an early-stage biofilm. Thus, a combination of L. rhamnosus and CP has greater potential to inhibit cariogenic biofilm formation than a single use of L. rhamnosus. Notably, a main tripeptide in collagen, Gly-ProHyp, showed similar activity as CP. Collagen consists of three polypeptide chains ( $\alpha$-chains) that are wrapped around each other to form triple-helical macromolecules, with glycine (Gly) in every third residue [27]. Based on the bioactivity of Gly-Pro-Hyp, the acidogenicity of $S$. mutans was significantly reduced.

How does CP modulate the metabolic traits of S. mutans? In this study, eno, ldh, and $a t p D$ genes expression was down-regulated, while $a g u D$ gene expression was upregulated in $S$. mutans by $\mathrm{CP}$ treatment, indicating $\mathrm{CP}$ plays a crucial role in metabolic interference via modulating the acidogenic and aciduric properties of $S$. mutans to reduce its cariogenic potential. These findings complement previous laboratory and clinical studies that have demonstrated that exogenous arginine supplementation (as an adjunctive anticaries agent) can modulate cariogenic biofilm formation via the arginine deiminase system in arginolytic bacteria (e.g., S. gordonii) by enhancing ammonia production [28-30]. Although arginine does not affect $S$. mutans directly, CP can modulate the metabolic traits of S. mutans. However, influences of CP on the fitness of commensal bacteria remain unknown, a lacunae that could be addressed through a multi-omics study of the harboring metatranscriptomics and metabolomics in multi-species biofilms. Additionally, it would be interesting to investigate how CP (or Gly-Pro-Hyp) modifies cell metabolism at the cytoplasmic level, which can be done by tracking a fluorescent or radiolabeled peptide on $S$. mutans. This tracking system enables the visualization of a localized peptide in the cytoplasm or on the membrane, or quantification of a metabolized or unmetabolized peptide in a culture medium. 
Since this study is based on well-controlled in vitro assays, further study will be necessary before it can be confirmed whether treatment with probiotics and prebiotics affects the ecology of oral microbiota in vivo, including the proportion and distribution of bacterial species in plaque biofilms. In a future study, we intend to assess the microbial diversity and functional potential of plaque biofilm in a disease or disease-modulating state (dealing with different biofilm developmental stages) as effected by oral-administered oral probiotics and prebiotics. This synbiotic is a potential candidate for an oral healthpromoting strategy that operates via inhibiting the virulence potential of S. mutans (Figure 8). We anticipate that this will enhance the understanding of the therapeutic potential of synbiotics and their fundamental role in the pathogenesis of severe tooth decay.

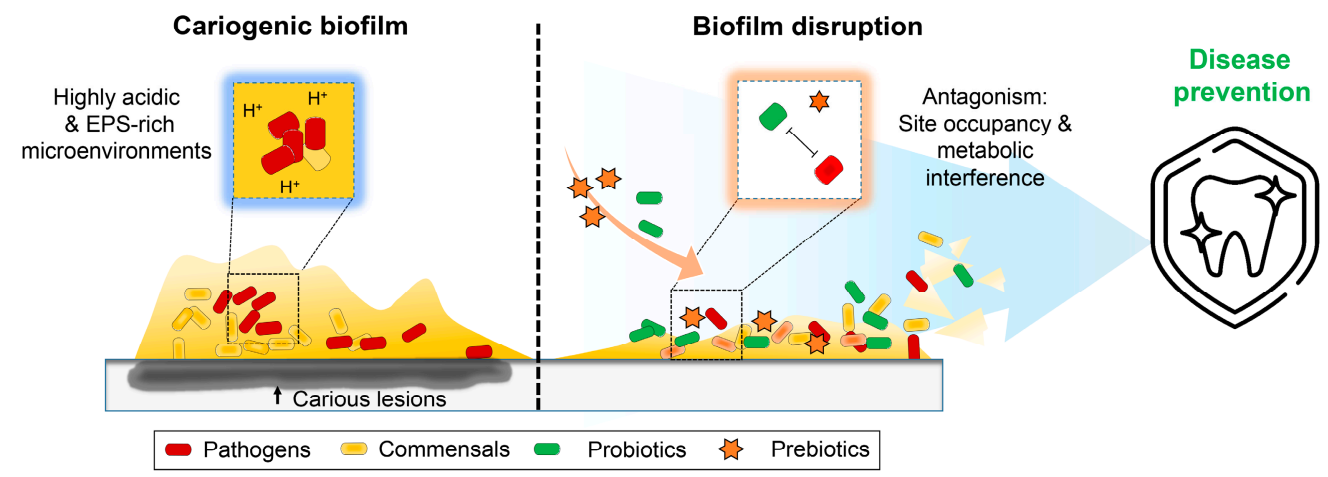

Figure 8. Schematic diagram for synbiotic approach to the disruption of cariogenic biofilm that prevent dental caries.

\section{Materials and Methods}

\subsection{Bacterial Strains and Culture Condition}

Streptococcus mutans UA159 (an established cariogenic dental pathogen and wellcharacterized EPS producer) were used to generate single- or mixed-species biofilms. Lactobacillus rhamnosus GG $\left(\mathrm{LGG}^{\circledR}\right.$, well-characterized and commonly used as a probiotic strain) was provided from Chr. Hansen, Hørsholm, Denmark. This strain maintains genomic and phenotypic stability throughout the industrial freeze-drying process [31]. For inoculum preparation, S. mutans and L. rhamnosus cells were grown to the mid-exponential phase (optical density at $600 \mathrm{~nm}\left(\mathrm{OD}_{600}\right)$ of 0.65 and 0.5 , respectively) in ultrafiltered (10-kDa molecular-mass cutoff membrane; Millipore, Danvers, MA, USA) tryptone-yeast extract broth (UFTYE; $2.5 \%$ tryptone and $1.5 \%$ yeast extract (BD Biosciences, San Jose, CA, USA)) with $1 \%(w / v)$ glucose at $37{ }^{\circ} \mathrm{C}$ and $5 \% \mathrm{CO}_{2}$, using a process described previously [32].

\subsection{Bacterial Cell Response to Collagen Peptide (CP)}

Bacterial cell responses were determined on the agar plate supplemented with $\mathrm{CP}$ (Soluge ${ }^{\circledR}$ Prima PP, PB Leiner, Davenport, IA, USA). To assess cell viability of $S$. mutans and L. rhamnosus after exposure to $\mathrm{CP}$, a $5 \mu \mathrm{L}$-aliquot of serially diluted cell suspensions (with cell densities ranging from $10^{3}$ to $10^{7} \mathrm{CFU} / \mathrm{mL}$ ) were spotted on $\mathrm{CP}$ containing brain heart infusion (BHI) agar (BD Biosciences) plates. Cell-cell interaction, specifically competition between L. rhamnosus and S. mutans $\left(10^{5} \mathrm{CFU} / \mathrm{mL}\right)$, involved testing of variable inoculums size $\left(10^{5-7} \mathrm{CFU} / \mathrm{mL}\right)$ of L. rhamnosus. To examine the competition, simultaneous point inoculation both strains of which S. mutans was spotted on the next to L. rhamnosus in BHI agar and incubated for $24 \mathrm{~h}$ or $48 \mathrm{~h}$ (if the competitive interaction is not observed).

\subsection{Glycolytic $\mathrm{pH}$ Drop Assay}

The effect of $\mathrm{CP}$ on glycolytic acid production by $S$. mutans planktonic cells was measured, as described elsewhere [33]. Briefly, S. mutans or L. rhamnosus cells in the planktonic cultures were harvested, washed once with a salt solution $(50 \mathrm{mM} \mathrm{KCl}+1 \mathrm{mM}$ $\mathrm{MgCl}_{2}, \mathrm{pH}=7$ ), and resuspended in a salt solution. The $\mathrm{pH}$ was adjusted to 7.0 with $0.2 \mathrm{M}$ 
$\mathrm{KOH}$ solution. Glucose was then added to obtain a concentration of $1 \%(w / v)$, and $\mathrm{pH}$ change was assessed over a period of 90 min using a glass electrode (Orion 3-Star, Thermo Scientific, Waltham, MA, USA). The initial rate of acid production, which provides the best measure of the acid production capacity of the cells, was calculated using $\mathrm{pH}$ values.

H-Gly-Pro-Hyp-OH (Bachem, Bubendorf, Switzerland), a common tripeptide unit of collagen, was used for testing. Glycine (Shijiazhuang Shixing Amino Acid Co., Ltd., Shijiazhuang, China), one of most abundant amino acids in CP, was also used to compare the activity of CP. H-Gly-Pro-Hyp-OH, glycine, and CP were used at $5 \mathrm{mg} / \mathrm{mL}(0.5 \%(w / v))$.

\subsection{In Vitro Biofilm Model}

Biofilms were formed on hydroxyapatite (HA) discs (surface area, $2.7 \pm 0.2 \mathrm{~cm}^{2}$ ) vertically suspended in 24-well plates using a custom-made wire specimen holder. For the in vitro competition model, well-established cariogenic pathogen $S$. mutans and wellcharacterized probiotic L. rhamnosus were grown in UFTYE with $1 \%$ glucose at $37^{\circ} \mathrm{C}$ and $5 \% \mathrm{CO}_{2}$. Each of the bacterial suspensions were then mixed to provide an inoculum with a defined microbial population of $S$. mutans $\left(10^{5} \mathrm{CFU} / \mathrm{mL}\right)$ and L. rhamnosus $\left(10^{7} \mathrm{CFU} / \mathrm{mL}\right)$. The mixed population was inoculated in $2.8 \mathrm{~mL}$ of UFTYE containing $1 \%(w / v)$ sucrose with or without $\mathrm{CP}(5 \mathrm{mg} / \mathrm{mL})$ and incubated at $37^{\circ} \mathrm{C}$ and $5 \% \mathrm{CO}_{2}$. The culture medium was changed twice daily (at 9 am $(19 \mathrm{~h})$ and $6 \mathrm{pm}(28 \mathrm{~h})$ ) throughout the experimental period (at 19, 23, and $43 \mathrm{~h}$ ). The EPS were labeled with $1 \mu \mathrm{M}$ Alexa Fluor 647-dextran conjugate (Molecular Probes, Eugene, OR, USA) [34].

For the three-species biofilm model, pathogen $S$. mutans and commensal S. oralis KCTC 13038 (originated from ATCC 35037; this strain obtained from Korean Collection for Type Cultures (KCTC), Korea Research Institute of Bioscience and Biotechnology, Jeongeup, Korea) was used together with L. rhamnosus. Each bacterial suspension was mixed to provide an inoculum with $S$. mutans $\left(10^{3}\right)$, S. oralis $\left(10^{7}\right)$, and L. rhamnosus $\left(10^{7}\right)$. Whole salvia was collected for the preparation of pellicle-coated hydroxyapatite, mimicking the smooth surfaces of a pellicle-coated tooth. Consistent with the ecological plaque hypothesis, as previously established $[6,35]$, the mixed bacterial population was inoculated in UFTYE containing $0.1 \%(w / v)$ sucrose and then incubated for $19 \mathrm{~h}$ to form an initially colonized community on the surface. The initial biofilm was then transferred to UFTYE containing 1\% sucrose to stimulate a cariogenic challenge at $19 \mathrm{~h}$. The culture medium was changed at $28 \mathrm{~h}$ and the biofilm (43 h-old) was subjected to confocal imaging with species-specific labeling [25].

\subsection{Assessment of Gene Expression via qRT-PCR}

RNA was extracted and purified using protocols optimized for biofilms formed in vitro [36]. Briefly, disc sets were incubated in RNALater (Applied Biosystems / Ambion, Austin, TX, USA) and at $43 \mathrm{~h}$ the biofilm was removed from the HA discs. The RNAs were purified and DNAse were treated on a column using a Qiagen RNeasy Micro kit (Qiagen, Valencia, CA, USA). The RNAs were then subjected to a second DNaseI treatment with Turbo DNase (Applied Biosystems / Ambion) and purified using the Qiagen RNeasy MinElute Cleanup kit (Qiagen). Then, we performed qRT-PCR to measure the expression profiles of eno, $l d h$, atpD, and $a g u D$. Briefly, cDNAs were synthesized using $0.5 \mu \mathrm{g}$ of purified RNA and the BioRad iScript cDNA synthesis kit (Bio-Rad Laboratories, Inc., Hercules, CA, USA). The resulting cDNAs were amplified with an Applied Biosystem StepOne system using previously published specific primers: $l d h$, eno, atpD, aguD, and 16S rRNA [36-38]. Comparative expression was calculated by normalizing each gene of interest to the $16 \mathrm{~S}$ rRNA signal [39].

\subsection{Fluorescence In Situ Hybridization for Bacterial Cell Labeling in Biofilms}

3D architecture was analyzed via fluorescence in situ hybridization (FISH), as detailed previously [25]. Bacterial cells were labeled by using species-specific FISH probes: MUT590, 5'-ACTCCAGACTTTCCTGAC-3' with Cy3 for S. mutans; EUB338, 5'-ACAGCCTTTAACTT CAGACTTATCTAA-3' with FAM for all bacteria, including both $S$. mutans and L. rhamnosus. 
To separate the L. rhamnosus from EUB338-labeled cells, the computational subtraction method was applied [25]. For specific labeling of the three species in the multi-species biofilms, MUT590, 5'-ACTCCAGACTTTCCTGAC-3' with Cy3 for S. mutans; Lcai467, 5'-CCGTCACGCCGACAACAG-3' with FAM for L. rhamnosus; MIT588, 5'-ACAGCCTTTA ACTTCAGACTTATCTAA-3' with Cy5 for S. oralis $[25,40]$. The sample in the hybridization buffer (25\% formamide, $0.9 \mathrm{M} \mathrm{NaCl}, 0.01 \%$ SDS, $20 \mathrm{mM}$ Tris- $\mathrm{HCl}$, pH 7.2) with the probes was incubated at $46^{\circ} \mathrm{C}$ for $4 \mathrm{~h}$. After incubation, the hybridized cells were washed with washing buffer (0.2 M NaCl, $20 \mathrm{mM}$ Tris- $\mathrm{HCl}$ (pH 7.5), $5 \mathrm{mM}$ EDTA, 0.01\% SDS), and further incubated at $46^{\circ} \mathrm{C}$ for $15 \mathrm{~min}$.

\subsection{Confocal Laser Scanning Microscopy (CLSM)}

The 3D biofilm architecture was acquired using $\mathrm{C}^{+}$confocal microscope (Nikon, Tokyo, Japan) with $20 \times(0.75$ numerical aperture (NA)) or $40 \times(1.15 \mathrm{NA})$ objective. The biofilms were sequentially scanned using Diode lasers $(488,568$, and $640 \mathrm{~nm})$, and the fluorescence emitted was collected with the PMT detector (490-550 nm for FAM, 565-620 nm for Cy3, and 645-700 nm for Alexa Fluor 647 or Cy5). NIS-Elements software version 5.21 (Nikon) was used to create 3D renderings to visualize the architecture of the biofilms.

Quantitative analysis of cell/EPS biovolume was performed using COMSTAT version 1 (available as free download at http:/ / www.imageanalysis.dk (accessed on 10 January 2022)), written as scripts for MATLAB software (version 9.11, Mathworks, Natick, MA, USA).

\subsection{Statistical Analysis}

Data are presented as mean \pm standard deviations (SD). Data were analyzed using analysis of variance (ANOVA) with post hoc Tukey's HSD test for a multiple comparison or Student's $t$-test for a pair comparison. Differences between groups were considered statistically significant when $p<0.05$. Statistical analyses were performed using SPSS version 26.0 software (IBM, Armonk, NY, USA).

\section{Conclusions}

Our data show that the presence of L. rhamnosus and CP effectively modulates cariogenic biofilm formation, suggesting that a synbiotic approach may inhibit the virulence potential of $S$. mutans. These findings provide important insights that allow us to further understand the role of synbiotics and potentially develop a combinatorial treatment of probiotics and prebiotics that prevents a prevalent and costly oral disease.

Author Contributions: Conceptualization, H.-Y.J., J.-G.J. and D.K.; methodology, H.-Y.J., J.-G.J. and D.K.; validation, H.-Y.J., J.-G.J. and D.K.; investigation, H.-Y.J., J.-N.C. and D.K.; resources, S.C.Y., S.-H.K., J.-G.J. and D.K.; writing-original draft preparation, J.-N.C. and D.K.; writing-review and editing, J.-N.C. and D.K.; visualization, D.K.; supervision, D.K. All authors have read and agreed to the published version of the manuscript.

Funding: This work was supported by Vixxol Corporation and research funds for newly appointed professors of Jeonbuk National University in 2020 (D.K.). D.K. was also supported in part by the National Research Foundation (NRF) of Korea (grant no. 2021R1C1C1005317).

Institutional Review Board Statement: Ethical approval and written consent/permission forms was obtained from the Jeonbuk National University's Institutional Review Board (IRB ref. JBNU 2021-12-008-001).

Informed Consent Statement: All subjects provided written informed consent (no children participated in the saliva collection) pursuant to the protocol reviewed and approved by the Institutional Review Board at Jeonbuk National University (IRB ref. JBNU 2021-12-008-001).

Data Availability Statement: All gathered data are presented in the main text. Data are available upon request to the authors. 


\begin{abstract}
Acknowledgments: The biological resource (S. oralis KCTC 13038) used in this research were distributed from Korean Collection for Type Cultures (KCTC)). This paper was proofread by the Writing Center at Jeonbuk National University. The authors are grateful to Ye Han for the technical support.

Conflicts of Interest: S.C.Y., S.-H.K. and D.K. are named as inventors of a patent application on the use of L. rhamnosus in a combination of collage peptide for antibiofilm agents. The funders had no role in the design of the study, in the collection, analyses, or interpretation of data, in the writing of the manuscript, or in the decision to publish the results.
\end{abstract}

\title{
References
}

1. Vos, T.; Abajobir, A.A.; Abate, K.H.; Abbafati, C.; Abbas, K.M.; Abd-Allah, F.; Abdulkader, R.S.; Abdulle, A.M.; Abebo, T.A.; Abera, S.F.; et al. Global, regional, and national incidence, prevalence, and years lived with disability for 328 diseases and injuries for 195 countries, 1990-2016: A systematic analysis for the Global Burden of Disease Study 2016. Lancet 2017, 390, 1211-1259. [CrossRef]

2. $\quad$ Peres, M.A.; Macpherson, L.M.; Weyant, R.J.; Daly, B.; Venturelli, R.; Mathur, M.R.; Listl, S.; Celeste, R.K.; Guarnizo-Herreño, C.C.; Kearns, C.; et al. Oral diseases: A global public health challenge. Lancet 2019, 394, 249-260. [CrossRef]

3. Hajishengallis, E.; Parsaei, Y.; Klein, M.; Koo, H. Advances in the microbial etiology and pathogenesis of early childhood caries. Mol. Oral Microbiol. 2017, 32, 24-34. [CrossRef]

4. Xiao, J.; Huang, X.; Alkhers, N.; AlZamil, H.; Alzoubi, S.; Wu, T.T.; Castillo, D.A.; Campbell, F.; Davis, J.; Herzog, K.; et al. Candida albicans and Early Childhood Caries: A Systematic Review and Meta-Analysis. Caries Res. 2018, 52, 102-112. [CrossRef] [PubMed]

5. Kim, D.; Koo, H. Spatial Design of Polymicrobial Oral Biofilm in Its Native Disease State. J. Dent. Res. 2020, 99, 597-603. [CrossRef] [PubMed]

6. Bowen, W.H.; Burne, R.A.; Wu, H.; Koo, H. Oral Biofilms: Pathogens, Matrix, and Polymicrobial Interactions in Microenvironments. Trends Microbiol. 2018, 26, 229-242. [CrossRef]

7. Kim, D.; Liu, Y.; Benhamou, R.; Sanchez, H.; Simon-Soro, A.; Li, Y.; Hwang, G.; Fridman, M.; Andes, D.; Koo, H. Bacterial-derived exopolysaccharides enhance antifungal drug tolerance in a cross-kingdom oral biofilm. ISME J. 2018, 12, 1427-1442. [CrossRef]

8. Ren, Z.; Kim, D.; Paula, A.; Hwang, G.; Liu, Y.; Li, J.; Daniell, H.; Koo, H. Dual-Targeting Approach Degrades Biofilm Matrix and Enhances Bacterial Killing. J. Dent. Res. 2019, 98, 322-330. [CrossRef]

9. Culp, D.J.; Hull, W.; Bremgartner, M.J.; Atherly, T.A.; Christian, K.N.; Killeen, M.; Dupuis, M.R.; Schultz, A.C.; Chakraborty, B.; Lee, K.; et al. In Vivo Colonization with Candidate Oral Probiotics Attenuates Streptococcus mutans Colonization and Virulence. Appl. Environ. Microbiol. 2021, 87, e02490-20. [CrossRef]

10. Jiang, Q.; Kainulainen, V.; Stamatova, I.; Korpela, R.; Meurman, J.H. Lactobacillus rhamnosus GG in Experimental Oral Biofilms Exposed to Different Carbohydrate Sources. Caries Res. 2018, 52, 220-229. [CrossRef]

11. Fernández, C.E.; Giacaman, R.A.; Tenuta, L.M.; Cury, J.A. Effect of the Probiotic Lactobacillus rhamnosus LB21 on the Cariogenicity of Streptococcus mutans UA159 in a Dual-Species Biofilm Model. Caries Res. 2015, 49, 583-590. [CrossRef] [PubMed]

12. Toiviainen, A.; Jalasvuori, H.; Lahti, E.; Gursoy, U.; Salminen, S.; Fontana, M.; Flannagan, S.; Eckert, G.; Kokaras, A.; Paster, B.; et al. Impact of orally administered lozenges with Lactobacillus rhamnosus GG and Bifidobacterium animalis subsp. lactis BB-12 on the number of salivary mutans streptococci, amount of plaque, gingival inflammation and the oral microbiome in healthy adults. Clin. Oral Investig. 2014, 19, 77-83. [CrossRef] [PubMed]

13. Pham, L.C.; Hoogenkamp, M.A.; Exterkate, R.A.; Terefework, Z.; De Soet, J.J.; Cate, J.M.T.; Crielaard, W.; Zaura, E. Effects of Lactobacillus rhamnosus GG on saliva-derived microcosms. Arch. Oral Biol. 2011, 56, 136-147. [CrossRef] [PubMed]

14. Aminabadi, N.A.; Erfanparast, L.; Ebrahimi, A.; Oskouei, S.G. Effect of Chlorhexidine Pretreatment on the Stability of Salivary Lactobacilli Probiotic in Six- to Twelve-Year-Old Children: A Randomized Controlled Trial. Caries Res. 2011, 45, 148-154. [CrossRef]

15. Zaura, E.; Twetman, S. Critical Appraisal of Oral Pre- and Probiotics for Caries Prevention and Care. Caries Res. 2019, 53, 514-526. [CrossRef]

16. Bijle, M.N.; Ekambaram, M.; Lo, E.C.M.; Yiu, C.K.Y. Synbiotics in caries prevention: A scoping review. PLoS ONE 2020, 15, e0237547. [CrossRef]

17. Bijle, M.N.; Neelakantan, P.; Ekambaram, M.; Lo, E.C.M.; Yiu, C.K.Y. Effect of a novel synbiotic on Streptococcus mutans. Sci. Rep. 2020, 10, 7951. [CrossRef]

18. Steinert, R.E.; Sadabad, M.S.; Harmsen, H.J.M.; Weber, P. The prebiotic concept and human health: A changing landscape with riboflavin as a novel prebiotic candidate? Eur. J. Clin. Nutr. 2016, 70, 1348-1353. [CrossRef]

19. Griswold, A.R.; Jameson-Lee, M.; Burne, R.A. Regulation and Physiologic Significance of the Agmatine Deiminase System of Streptococcus mutans UA159. J. Bacteriol. 2006, 188, 834-841. [CrossRef]

20. Kanasi, E.; Dewhirst, F.; Chalmers, N.; Kent, R., Jr.; Moore, A.; Hughes, C.; Pradhan, N.; Loo, C.; Tanner, A.C.R. Clonal analysis of the microbiota of severe early childhood caries. Caries Res. 2010, 44, 485-497. [CrossRef]

21. Eren, A.M.; Borisy, G.G.; Huse, S.M.; Welch, J.L.M. PNAS Plus: From the Cover: Oligotyping analysis of the human oral microbiome. Proc. Natl. Acad. Sci. USA 2014, 111, E2875-E2884. [CrossRef] [PubMed] 
22. Johansson, I.; Witkowska, E.; Kaveh, B.; Lif Holgerson, P.; Tanner, A.C.R. The Microbiome in Populations with a Low and High Prevalence of Caries. J. Dent. Res. 2016, 95, 80-86. [CrossRef] [PubMed]

23. Kolenbrander, P.E.; Palmer, R.J., Jr.; Periasamy, S.; Jakubovics, N.S. Oral multispecies biofilm development and the key role of cell-cell distance. Nat. Rev. Microbiol. 2010, 8, 471-480. [CrossRef] [PubMed]

24. Olsen, I. Organization of supragingival plaque at the micron scale. J. Oral Microbiol. 2018, 10, 1438722. [CrossRef]

25. Kim, D.; Barraza, J.P.; Arthur, R.; Hara, A.; Lewis, K.; Liu, Y.; Scisci, E.L.; Hajishengallis, E.; Whiteley, M.; Koo, H. Spatial mapping of polymicrobial communities reveals a precise biogeography associated with human dental caries. Proc. Natl. Acad. Sci. USA 2020, 117, 12375-12386. [CrossRef]

26. Koo, H.; Allan, R.N.; Howlin, R.P.; Stoodley, P.; Hall-Stoodley, L. Targeting microbial biofilms: Current and prospective therapeutic strategies. Nat. Rev. Microbiol. 2017, 15, 740-755. [CrossRef]

27. Shoulders, M.D.; Raines, R.T. Collagen Structure and Stability. Annu. Rev. Biochem. 2009, 78, 929-958. [CrossRef]

28. Koopman, J.E.; Röling, W.F.M.; Buijs, M.J.; Sissons, C.H.; Cate, J.M.T.; Keijser, B.J.F.; Crielaard, W.; Zaura, E. Stability and Resilience of Oral Microcosms Toward Acidification and Candida Outgrowth by Arginine Supplementation. Microb. Ecol. 2014, 69, 422-433. [CrossRef]

29. He, J.; Hwang, G.; Liu, Y.; Gao, L.; Kilpatrick-Liverman, L.; Santarpia, P.; Zhou, X.; Koo, H. L-Arginine Modifies the Exopolysaccharide Matrix and Thwarts Streptococcus mutans Outgrowth within Mixed-Species Oral Biofilms. J. Bacteriol. 2016, 198, $2651-2661$. [CrossRef]

30. Nascimento, M.; Browngardt, C.; Xiaohui, X.; Klepac-Ceraj, V.; Paster, B.; Burne, R. The effect of arginine on oral biofilm communities. Mol. Oral Microbiol. 2014, 29, 45-54. [CrossRef]

31. Stage, M.; Wichmann, A.; Jørgensen, M.; Vera-Jimenéz, N.I.; Wielje, M.; Nielsen, D.S.; Sandelin, A.; Chen, Y.; Baker, A. Lactobacillus rhamnosus GG Genomic and Phenotypic Stability in an Industrial Production Process. Appl. Environ. Microbiol. 2020, 86, e02780-19. [CrossRef] [PubMed]

32. Kim, D.; Sengupta, A.; Niepa, T.H.R.; Lee, B.-H.; Weljie, A.; Freitas-Blanco, V.; Murata, R.M.; Stebe, K.J.; Lee, D.; Koo, H. Candida albicans stimulates Streptococcus mutans microcolony development via cross-kingdom biofilm-derived metabolites. Sci. Rep. 2017, 7, srep41332. [CrossRef] [PubMed]

33. Jeon, J.G.; Pandit, S.; Xiao, J.; Gregoire, S.; Falsetta, M.L.; Klein, M.I.; Koo, H. Influences of transtrans farnesol, a membranetargeting sesquiterpenoid, on Streptococcus mutans physiology and survival within mixedspecies oral biofilms. Int. J. Oral. Sci. 2011, 3 , 98-106. [CrossRef] [PubMed]

34. Xiao, J.; Klein, M.I.; Falsetta, M.L.; Lu, B.; Delahunty, C.M.; Yates, J.R.; Heydorn, A.; Koo, H. The Exopolysaccharide Matrix Modulates the Interaction between 3D Architecture and Virulence of a Mixed-Species Oral Biofilm. PLoS Pathog. 2012, 8, e1002623. [CrossRef] [PubMed]

35. Philip, N.; Suneja, B.; Walsh, L.J. Ecological Approaches to Dental Caries Prevention: Paradigm Shift or Shibboleth? Caries Res. 2018, 52, 153-165. [CrossRef] [PubMed]

36. He, J.; Kim, D.; Zhou, X.; Ahn, S.-J.; Burne, R.A.; Richards, V.; Koo, H. RNA-Seq Reveals Enhanced Sugar Metabolism in Streptococcus mutans Co-cultured with Candida albicans within Mixed-Species Biofilms. Front. Microbiol. 2017, 8, 1036. [CrossRef]

37. Jeon, J.-G.; Klein, M.I.; Xiao, J.; Gregoire, S.; Rosalen, P.L.; Koo, H. Influences of naturally occurring agents in combination with fluoride on gene expression and structural organization of Streptococcus mutans in biofilms. BMC Microbiol. 2009, 9, 228. [CrossRef]

38. Cai, J.-N.; Jung, J.-E.; Lee, M.-H.; Choi, H.-M.; Jeon, J.-G. Sucrose challenges to Streptococcus mutans biofilms and the curve fitting for the biofilm changes. FEMS Microbiol. Ecol. 2018, 94, fiy091. [CrossRef]

39. Cury, J.A.; Koo, H. Extraction and purification of total RNA from Sreptococcus mutans biofilms. Anal. Biochem. 2007, 365, 208-214. [CrossRef]

40. Quevedo, B.; Giertsen, E.; Zijnge, V.; Lüthi-Schaller, H.; Guggenheim, B.; Thurnheer, T.; Gmür, R. Phylogenetic group- and species-specific oligonucleotide probes for single-cell detection of lactic acid bacteria in oral biofilms. BMC Microbiol. 2011, 11, 14 [CrossRef] 